\section{Networking knowledge}

Scholarship in the Digital Age: Information, Infrastructure and the Internet

by Christine L. Borgman

MIT Press: 2007.336 pp. $\$ 35$

\section{Richard Akerman}

The invisible college is becoming visible as the Internet enhances the ability to exchange scientific information. More open science is enabled by lifting constraints on communication and allowing broader and richer dissemination and discussion of theories and results. Academia and society are running to keep up with the changes in technology and the expanding capacity of scholarly infrastructure. New business models and academic reward systems are also burgeoning.

Scholarship in the Digital Age provides an overview of these transformations from a rigorous historical perspective that is couched in well-defined terminology. As Christine Borgman points out, "This is an opportune moment to think about what sort of scholarly environment we should be building ... while the new technologies receive the most attention, it is the underlying social and policy changes that are most profound.'

Borgman focuses on scholarly communications practices and issues, encompassing all domains of science. She presents the academic information system as embedded in and constrained by a complex socio-political environment. Her perspective provides a useful balance to the ambitious and sometimes utopian technology focus of major e-research projects.

To frame the problem, Borgman looks first at the essentials of scientific communication, describing the mechanics of peer-reviewed publication, the range of conference types and contributions by authors. Although wellworn ground for seasoned scientists, this is a good foundation for assessing the impact of the Internet on the dissemination of science.

It is to the disruptive impact of the Internet on science that Borgman turns next, exploring the challenges caused by openly circulating digital information, particularly issues for scientific publishers. Although there is a benefit to society because the closed social networks that used to form invisible colleges of researchers have now opened up, their erudite discussion, painstakingly gathered data and solid research are now sharing space - and competing for search ranking - with materials of questionable quality and legitimacy.

How does one select, register and certify research documents in a networked digital environment? And how can one locate quality articles, particularly when much of the record is available only to licensed users and may be poorly represented in general search results? A detailed discussion of open access ensues, including issues of intellectual property and copyright, as well as commons approaches, such as Creative Commons (http://creativecommons.org), in which content creators may grant a limited set of rights, explicitly permitting use for public purposes.

Borgman then discusses data and all their aspects - from basic definitions and new types to increasing volumes of data and their role in scientific communication. She revisits certification, curation and intellectual-property issues for data, which are subject to different conventions to that of publications.

The author sets up her concept of an "advanced scholarly information infrastructure" based on her research and explicitly set within a framework of open science as a public good. In her description of the infrastructure, there is little in the way of technical guidance and the focus is on the behaviour and patterns of different disciplines, the nature of academic artefacts (such as books and journal articles) and on the conventions and etiquette of collaboration. Indeed, the topic of collaboration in various sections of the book - consistent with the non-technical focus - includes no mention of 'wikis' (websites for collaboratively editing and sharing text, such as Wikipedia).

Scholarship in the Digital Age concludes with a compelling discussion of the research problems that a comprehensive scientific cyberinfrastructure will need to address. The author points out the necessity of taking a long-term view of content, to balance local and global requirements. Also, there is a need to separate content from tools and services (thereby creating a 'content layer' that gives a coherent view of all content types), and to identify tools, technologies and institutional mechanisms to balance the coherence and control of the content layer. Thus, it creates a compromise between the desire of scientists for unfettered direct access and the needs of content-owners to control access.

Science policy-makers would do well to refer to this book in framing their aspirations for a scholarly infrastructure. Students of information science, as well as those seeking to understand science in our digital age, will find it a valuable reference and starting point. In a world where scientific networks and communication are now increasingly visible and open, Borgman has illuminated the discussion of the scholarly communication system itself.

Richard Akerman is a technology architect at the National Research Council Canada Institute for Scientific and Technical Information, 1200 Montreal Road, Ottawa, Ontario K1A 0R6, Canada.

\section{Parallel lives}

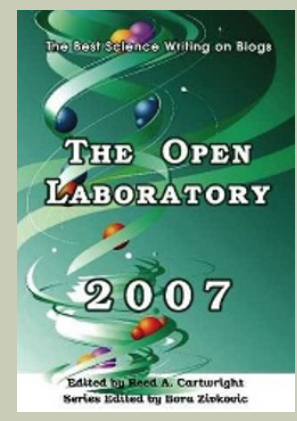

The editor of this second anthology of the best scientific communiqués from the blogosphere thinks blogs offer new ways to discuss science. The Open Laboratory 2007: the Best

Science Writing on Blogs (Lulu.com, 2008) takes the curious approach of using dead tree format to highlight the diversity of scientific ideas, opinions and voices flowing across the Internet. Every year a different guest editor here Reed Cartwright, a blogger and genetics and bioinformatics postdoc from North Carolina State University - picks the best posts to coincide with the Science Blogging Conference (in North Carolina on 19 January). First-hand accounts bring to life the stresses of a graduate student, a mother returning to the bench and an archaeologist's joy at unearthing mammoth fossils. Topics tackled are as varied as the writers, from Viagra and tapeworms to trepanning. Explanations are often offered with a personal twist, such as a father's tale of his child's Asperger's syndrome. The measured voices of trustworthy academics make medical research easy to swallow. If you are overwhelmed by the surge in science-related blogging and don't know where to start, then this compilation may help you steer a course through the sea of perspectives on offer - or inspire you to start a blog yourself.

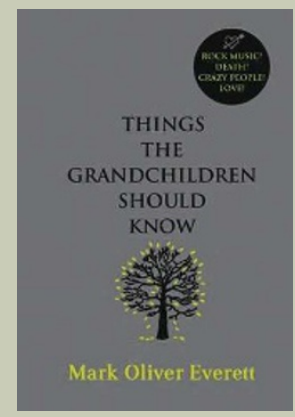
Mark Oliver Everett sought to understand the world through music, not science. The lead singer of US rock group Eels made sense of his troubled family history first via song-writing and now in an

autobiography - Things the Grandchildren Should Know (Little, Brown, 2008). His late father, the physicist Hugh Everett III, suggested the radical idea of parallel worlds in quantum theory - every time a certainty is measured, the universe splits in two parallel strands, each with a different outcome. The breadth of his father's ideas are not lost on Mark, who poignantly links them to his sister's suicide: in one world she may be dead, yet in another alive. It is an intriguing personal perspective on an influential scientist's life from his family and to note the impact his science made on a young man with a powerful messenger, the guitar. J.B. 